\title{
El Amor al Borde de la Guerra
}

\section{Love in the brink of war}

\section{Jhonattan Andrés Benavides Jurado}

Estudiante del programa de Literatura

Universidad Autónoma de Bucaramanga

jbenavides158@unab.edu.co

\section{I}

Isabela Contri o simplemente Isa, como solían llamarle incluso antes de su bautismo, pasó la mañana del 27 de agosto de 1975 frente a las ruinas de su escuela en San Juan de Limay, con la misma expresión de perplejidad que debió dibujarse en su rostro cuando escuchó por tercera vez que el mundo entero estaba viviendo una guerra fría. Si niña le llamaban en las calles desoladas, en las que los varones brillaban por su ausencia a causa de su temprano reclutamiento en las filas sandinistas, la guerra le llamaba señora y le hacían venia al cruzar frente a ella, tal como ocurrió cuando sus ojos contemplaron la natural belleza de María Asunción, la mujer que, en aquella ocasión, caminaba en puntas de pies para no pisar los clavos y las esquirlas de vidrio que habían quedado en el suelo tras el estallido de la bomba que no respetó ni el último atisbo cultural de aquel municipio nicaragüense.

Las manchas de polvo en el rostro de la dama no impidieron que Isabela se detuviera, como en un éxtasis, a contemplar su liso y negro cabello, su piel canela, sus ojos negros y sus galantes hombros, dignos de soportar el manteo de una emperatriz. Qué fácil le resultó confundir entonces aquella sensación corporal de nerviosismo con el vago recuerdo de las manos de su madre acariciando sus mejillas o el suave cosquilleo que producían las flores cuando se acercan a la nariz.

Antes de que pudiera desplomarse en el suelo o permitiera a la maestra notar sus mejillas sonrojadas, advirtió Isabela el grito silencioso de quien ahora reclamaba ayuda para levantar los escombros. Salió corriendo en dirección contraria, como alma que lleva el diablo, y convenció a otras mujeres que se ocultaban, por temor a un bombardeo, de ayudar a descubrir los últimos objetos recuperables de aquellas ruinas.

Si a los diez años pudiera haberse enamorado una niña de una maestra experimentada en el arte de educar, 
Isabela no podría haber llamado amor a ese repentino deseo de darse por completo, pues fácilmente lo habría interpretado como la mayor de las locuras o el mayor pecado, capaz de ser condenado a sangre y fuego, como le estaba ocurriendo entonces a su pueblo.

Pasaron ellas la mañana y la tarde en aquel infructuoso oficio de rescatar algo valioso de entre los escombros, hasta entender que era tiempo de volver a casa. Isa, por su parte, fue incapaz de retornar sin agudizar en su memoria la imagen que despertaba el deseo inocente de atravesar, con sus dedos, la larga cabellera de María Asunción.

Los más de treinta años de vida de esta maestra, oriunda de Managua, habían sido suficientes para que la consideraran digna de ser enviada a tan afligido pueblo como maestra suplente, para que contratacara la deserción escolar; si bien, en un mes de labores no había conseguido el retorno de una sola niña a la escuela, quedaba claro, desde aquel primer encuentro con la pequeña Isa, que le habría bastado llamar a la puerta de madera del albergue de su familia, para ganar a su más ferviente alumna, a quién se le habría ido la vida convenciendo a más niñas de sustentar la misión de la nueva maestra.

Nada, fuera de este encuentro, había sido tan oportuno, hasta ahora, para una chiquilla que tenía a su cargo el cuidado de sus hermanos menores y la sustentación de un hogar merecedor únicamente de las manos heridas de una madre casi enloquecida por el llanto que de sus ojos brotaba tras los inconsolables anuncios de muertes sucesivas, fruto de disputas entre tropas revolucionarias y soldados entrenados para sustentar la existencia de una dictadura al servicio del País del Norte.

La primera vez que Isa preguntó por el significado de la expresión guerra fría, el rostro de su madre pareció rasgarse y en un grito se le oyó decir: ¡frío el infierno al que todos iremos! Necesitó preguntar una segunda vez a un vecino trovador que luego fue reclutado y él, con no menor aflicción que la de su madre y con aire de melodía, supo referir que el frío significaba: -“el congelamiento de una guerra que se esperaba estallase en cualquier momento y que el mundo ignoraba que había cobrado sangre en el sur desde hacía tiempo"-.

La tercera vez, como ya fue referido, tras escuchar la misma expresión en la radio, Isa rompió en llanto. Quizás había comprendido, con mayor agudeza, que su niñez estaba condenada a ser la vivencia anticipada de una madurez indeseada. ¿Qué cosa diversa de aflicción, dolor y desamparo podría describir el corazón de una mujer que a tan corta edad había teñido sus vestidos con el color de la sangre y no conocía la pureza más que en el agua del lago a donde solía acudir para bañarse?

\section{II}

Isabela era hija de un agricultor trabajador y disciplinado, incapaz de ahorrarse cualquier esfuerzo en la 
defensa de su honor, que no le venía de poder o posesión alguna, sino de su honestidad y de su honradez. Joven aún, había contraído nupcias con la bella Rosario, mujer esmerada en la formación de sus hijos y merecedora de un gran nombre entre las cocineras de la región, por ser los suyos los mejores guisos que nadie hubiese probado antes. Inexpertos pero llenos de bondad y de buenas intenciones, celebraron el nacimiento de su hija, a quien bautizaron según el rito católico, único conocido en San Juan desde que cualquiera tuviese memoria, cuatro años antes de que nacieran Domingo y Antonio, los gemelos que quedarían a cargo de su hermana mayor tras el estallido de la guerra. Si Isa había heredado la bondad de sus padres, el ahínco de su progenitor y la belleza latina de Rosario, la soledad le había regalado el valor y le había arrebatado la sonrisa.

Como todo buen obrero de las veredas de San Juan, el esposo de Rosario supo ingeniarse la manera de construir una casa de madera, inmune a las tormentas y a las oleadas de calor, aunque no a los misiles ni a las balas que más tarde la penetrarían. En aquella vivienda, se alimentaban de felicidad Rosario, sus hijos y el señor Contri. Por entonces, la organización veredal era incipiente pues no se necesitaba más que un juez para resolver pequeños asuntos de riñas y un líder que advirtiera de los peligros del sector, que se reducían a uno o a dos, esto es, a la posible contaminación de las aguas y a la falta de un cura que presidiese los oficios religiosos. No era que Don Chepe, como solían llamar al discípulo silencioso de Ernesto Cardenal, hubiese dejado de auxiliarlos sacramentalmente, sino que pasaba sus días errando de vereda en vereda, celebrando misas, confesando cristianos y recitando versos como estos: -Te ensalzaré en la reunión de nuestro pueblo, resonarán mis himnos en medio de un gran pueblo. Los pobres tendrán un banquete, nuestro pueblo celebrará una gran fiesta, el pueblo nuevo que va a nacer.

De mañanita las mujeres se congregaban en el lago para limpiar uno que otro trasto de tamaño gigante o para lavar las ropas acumuladas de una semana. El buen juicio de Rosario le permitió ingeniarse la manera de llegar al lago antes que todas sus vecinas, a fin de no tener que participar en los chismorreos que iban y venían a cierta hora de la mañana. Su esposo, que pasaba el día en los campos, arando, sembrando o cosechando, también había hallado la forma de mantenerse alejado de los informes que llegaban con cierta periodicidad de los cabecillas del FSLN, quienes nunca habían dejado de reclutar simpatizantes y cuya tarea integracionista fue aún más exhaustiva los años consiguientes.

La primera partida obligada de la mayoría de los hombres de San Juan hacia los oscuros refugios selváticos de los sandinistas acaeció un día cualquiera de 1974. Sólo algunos adolescentes varones, lograron escapar de la oleada reclutadora. Si bien, no todos habían partido queriendo participar de la guerra, todos eran conscientes de que su resistencia les habría valido el martirio de sus familias.

Rosario, tanto como las mujeres de su región, vieron venir entonces, tras la partida de sus maridos a la guerra, un huracán de llantos y desesperación. Antes de que pasaran once meses sin reporte alguno de la 
suerte de los combatientes, la valiente mujer de belleza en decadencia, perdió sus estribos sin creerse ya capaz de esperar tanto. Nueve años contaba la pequeña Isabel, que en aquel entonces debió madurar sin excusa ni remordimiento: sus juguetes fueron remplazados por trastos y sus tardes de rondas y golosas, intercambiadas por soleadas o lluviosas jornadas de trabajo.

Parece que treinta años de vida no eran capaces de sustentar tanta esperanza. Sin embargo, la desilusión de Rosario fue la ilusión creciente de su hija, quien no escatimó esfuerzos en el cuidado de sus hermanos, en la paciente espera de su padre, ni en el consuelo diario de su madre. Para 1975, cuando el ataque más cruento llegó hasta las veredas de San Juan, los rasgos infantiles de Isabela habían desaparecido casi por completo y en su lugar se iba dibujando una belleza adulta que se develaba perfectamente en sus senos firmes, su cuerpo delgado, su mirada atenta y su voz decidida.

III

Pasados sólo unos días, como parecía obvio que debiera ocurrir, Isabela volvió a experimentar la agitación de su respiración al acercarse al lago y contemplar, de repente, cerca de la orilla opuesta, el fin de la apnea de María Asunción. Allí, en los escasos días de tregua, confluían nativos y visitantes para quitarse de encima el aroma de la violencia, de modo que, una vez más, la niña pudo examinar, no ya entre escombros sino entre la gente, los aires encantadores y sobresalientes de la maestra, sin que ésta pudiera siquiera notar su presencia.

No hubo testigo de esa mirada perpleja ni lo hubo tampoco del grito silencioso que se desprendió de lo profundo del corazón de la niña reclamando la cercanía de María. Su temor, cada vez más violento, consiguió atraer la atención de una de las mujeres que reposaba a su lado insinuando con su mirada una pregunta que, sin ser pronunciada, obtuvo respuesta de parte de Isabela: -“no es nada, quizás sólo es otro mal presentimiento."

El llanto de uno de los gemelos le hizo volver en sí y corrió para auxiliarlo tras el golpe que le había propinado su hermano. Una vez volvió la mirada hacia el lago, sólo percibió un vacío en el lugar en el que su mirada debió haber avistado un monumento a la belleza y, reclamándose a sí misma con el ceño fruncido y los puños cerrados, deseó haber ignorado a sus hermanos.

De vuelta a casa halló en el camino los recuerdos que le hacían divagar como sólo lo haría un adulto. Pensaba en ellos y se imaginaba qué sería de su vida sin sus tristes secuelas en los invisibles álbumes fotográficos de la gente de su pueblo. Los rastros de balas, el ruido de tiroteos atraído por el viento, la sangre en las ramas de los árboles y los techos de las casas caídos e improvisados con nuevas piezas de madera y cartón confundidos, hacían pensar en el fin de los tiempos o en el origen caótico de la nada, en el que la 
esperanza se apaga y la fe, nadando en el vacío, cede su lugar al sinsentido.

Los gemelos caminaban a su lado, con la inocencia inexplicablemente conservada. Sonreían y discutían para volver a sonreír y halar de la falda de Isabela cada vez que tenían una queja. Todo en ellos era diversión y aventura, mientras en su hermana era nostalgia y desventura. Llegados a casa, mamá se encontraba levantando y tirando, de forma neurótica, las colchas llenas de retazos que cubrían la cama en tiempos de frío.

Hacía mucho que Isabela podía hablar con Rosario sin saber lo que pasaba por su mente ni obtener respuesta a sus preguntas. Resulta fácil imaginar que desde el instante en el que la escena de la escuela destruida, tratando de ser rescatada por las manos débiles de una maestra, quedó grabada en su memoria, Isabela pasara horas enteras contando a su madre todos los secretos del despertar de esa sensibilidad oculta entre los infantiles rasgos de su cuerpo.

IV

Aquellos eran los tiempos en los que María Asunción no perdía aún la esperanza de aplicar su experiencia pedagógica entre los pequeños de San Juan. Sin proclamarlo a grandes voces, la suya era una revolución contra los sandinistas y contra los simpatizantes de Somoza. En otras palabras, aunque su lucha no tenía bando, se oponía a todos los bandos habidos y por haber.

La madrugada de ese día, su mirada volvió a contemplar la valentía de Isabela cuando, pasando por su casa, la halló cargando un bulto de algo que parecía ser papa y que no consiguió divisar con total claridad. Ciertamente se trataba de la misma adolescente que, semanas atrás, había ido en busca de ayuda para colaborar con la remoción de los escombros. No había conseguido darle las gracias y, sin embargo, no le había olvidado del todo.

Una vez se hubo acercado, Isabela soltó aquello que traía en brazos y saludó a la maestra cordialmente. Ésta debió ser la única ocasión en la que sus manos se estrecharon. Fue inevitable para María sentirse especialmente valorada con aquel saludo. Sintió como si éste le viniera de una amiga muy querida y no de una desconocida, a quien apenas veía por segunda vez. La niña, por su parte, que no tenía quince años, como lo pensó la maestra, sino diez, aunque no pareciera, sintió en aquel instante la eternidad del tiempo. Si alguna vez percibió los segundos dilatándose, fue en cada nuevo encuentro con la mujer de alta estatura, rasgos femeninos pronunciados y ojos brillantes como no los había visto en ningún rostro conocido.

Tocar su mano fue para Isabela el más dulce néctar que hubiese probado, aunque luego sintiera vergüenza de haberla retenido durante tanto tiempo. Lo que no sabía era que para la maestra había sido tiempo suficiente, puesto que era natural que los niños de aquella región expresaran su timidez con nerviosismo o silencios inexplicables. Una vez le hubo soltado, la mujer de treinta años aprovechó la oportunidad para dar las gracias 
y hacer todo tipo de preguntas sobre el lugar donde se encontraba Anastasio, el informante de los sandinistas que residía en aquella región, camuflado entre la gente.

Fue entonces cuando Isabela vio el asomo de un mal presentimiento en su corazón y bastaron un par de minutos frente a los encantos de aquella dama, para percibir que algo terrible habría de ocurrirle si continuaba indagando cosas tan delicadas. Era casi innato saber muchos rumores sobre la violencia revolucionaria y caminar prevenidos frente a ellos, pero esto no era comprensible para los visitantes, aquellos que no habían respirado los humores de la guerra y que pretendían saberlo todo con un par de entrevistas, desprovistas de buenos augurios.

Isabela no perdió la oportunidad de advertir a la maestra sobre los riesgos que corrían quienes quisieran saber más de la cuenta. Sin embargo, María interpretó las palabras de la niña como un gesto generoso desprovisto de certeza: es que los niños temen muchas cosas y suelen creer en mitos fácilmente. Lo que ignoraba sobre la hija de Rosario y su esposo, era que ni era niña, ni temía a nada, ni creía en mito alguno. Su intuición, en cambio, le hizo percibir la incredulidad de María Asunción y no se lamentó por esto sino por la pena que le embargaba el saber que quien ahora tenía frente a sí, podría alcanzar la muerte en poco tiempo.

Las horas, que en realidad fueron minutos, pasaron dejando en el corazón de Isabela la sensación de haber visitado el cielo, de haber contemplado el rostro de un ángel y de haber escuchado a la muerte susurrándole palabras burlonas al oído. Sus piernas temblaban pero no era miedo, sus labios se abrían aunque no iba a pronunciar palabra, su piel se erizaba aunque no sentía frío, su rostro enrojecía aunque no estaba enferma.

Todo esto se juntó en un solo instante que Isabela relató a su madre con mayor intensidad que en ocasiones anteriores. La lucidez de Rosario, en otro tiempo, le habría cobrado un grito de escándalo al saber que su hija experimentaba lo mismo que ella experimentó en las primeras citas con el señor Contri, al besarlo, al abrazarlo y al soltarlo nuevamente para volver a empezar.

\section{V}

El tiempo que logró ganarle María Asunción a la salida del sol, fue el mismo tiempo que la muerte empeñó para alcanzar la vida de Isabela, su madre y sus dos hermanos. Cerca del refugio de Anastasio, en el camino que de la vereda conducía al centro de San Juan, vio el cielo teñirse de negro y el ambiente poblarse de sollozos y gritos. Allí, como si no tuviese en su memoria más lugar que para una niña tomando un bulto entre sus manos, corrió para deshacer el camino que había hecho hasta ahora.

Nadie más que la maestra conseguiría ver por última vez el rostro herido de la niña que le contempló como a una visión paradisiaca para preguntar, con la voz entrecortada, ¿por qué seguía ella con vida y su lugar le había sido arrebatado por una niña? Finalmente, la muerte cubrió con su sombra la mirada de Isabela al 
punto de que, ni siquiera entonces, la ternura de sus ojos consiguió transparentar totalmente el amor que había sentido por la maestra.

Un beso habría sellado esa corta historia de infantil deseo y silenciosa entrega, pero los ojos de Isabela se cerraron antes de que sus oídos escucharan el grito de María Asunción y antes de que su mejilla recibiera la de su amada para fundirse en un abrazo de dolor. Quizás, en medio de tan pesaroso drama, convino que el último segundo de lucidez Isa pensara no en una mujer que había retornado por miedo a lo que hubiese podido haber pasado, sino en una dama deseosa de presenciar la inminente partida de su taciturna enamorada.

Todo tenía sentido, aunque éste quisiera ocultarse: el camino que la mujer de treinta años había hecho aquella mañana le sirvió, sin siquiera presentirlo, para huir del bombardeo que cobró la vida de más de un centenar de mujeres y niños, a causa de un contraataque emprendido por las tropas de Somoza. En aquella ocasión nadie consiguió discernir, con total claridad, cuál fue el más insulso de los bandos, pues ambos cobraron su parte de muertes y sellaron un pacto de sangre que no culminaría hasta 1979.

El mundo entero se enteró al fin de la cruel mentira de la guerra fría. Supo entonces, que la solapada máscara que la ocultaba, había ido cobrando vidas en las periferias del sur. Así, mientras los países del norte no eran capaces de verse a la cara para cantarse sus verdades, tomaron como carnadas a sus vecinos del sur, para justificar el odio que no podía expresarse a grandes voces. Pocos, hasta ahora, saben de Isabela y de su amor por la maestra, pero muchos han llegado a conocer, sin por esto comprenderlo, el absurdo proceder de aquella guerra.

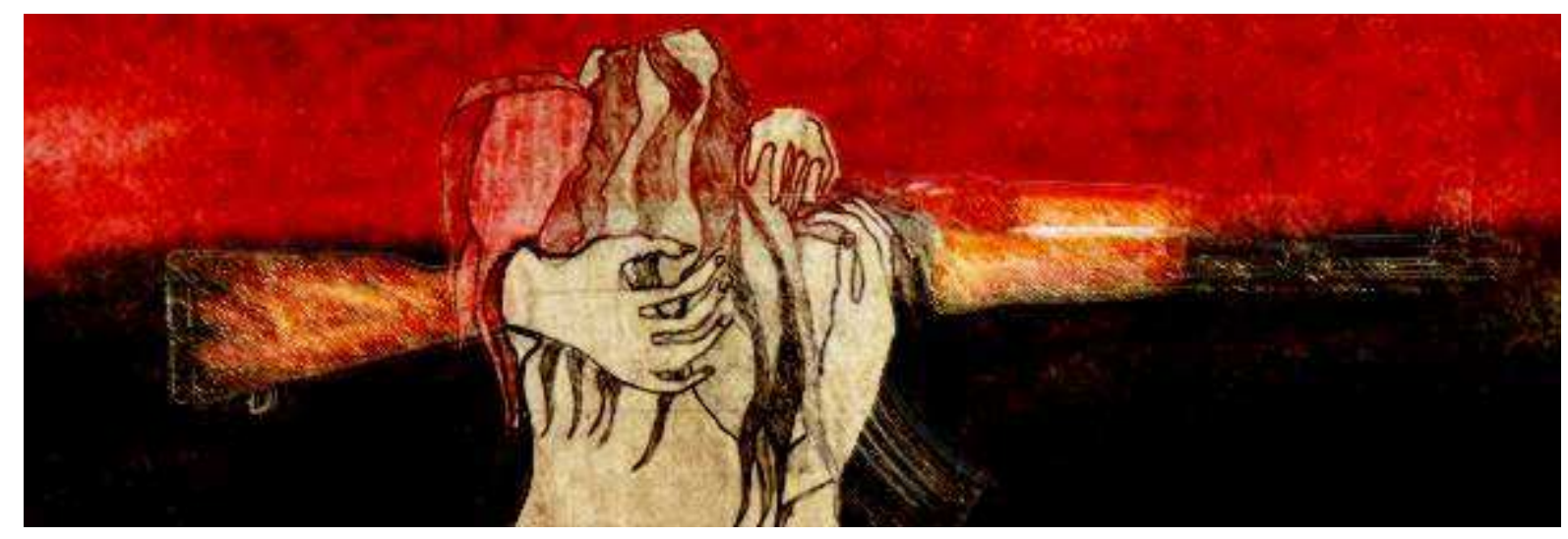

